Politzer's bag, which failed to improve the hearing) used were a gargle and nasal wash of weak salt-and-water, together with the induced current used daily as ahove described. At the beginning of this treatment the hearing distance was rather under two inches on the right side for a watch heard normally at thirty inches, and the tick was only audible to the left ear when the watch was almost in contact. After three days the hearing improved very considerably, and the patient could hear the same watch at three inches and a quarter from the right ear and one inch and a quarter from the left. A ratber interesting point in the case of a gentleman who suffered from exacerbations of chronic deafness after fatigue \&c., was that whereas before the application of the electric current he was quite unable to hear the vibrating tuning-fork hy boneconduction, immediately afterwards it was distinctly audible for a few seconds.

Edinburgh.

\section{ACUTE INTESTINAL OBSTRUCTION CAUSED BY IMPACTED GALL-STONE.}

\section{BX JOHN WA L TERS, M.B. LOND., AND \\ W. A. BERRIDGE, M.R.C.S., \&C.}

Mrs. G-, widow, aged sixty-nine, had always been tolerably healthy ; had suffered occasionally from bronchitis, and two years ago had an attack of acute recurring pain in the right side, called pleurisy, but no definite friction sound could be made out. She never was jaundiced; was in the habit of taking an aperient pill occasionally, and had lately become very stout. The patient was seized on the evening of February 2nd, 1880, with acute abdominal pain and vomiting; her bowels had acted freely during the day. When seen about 11.30 P.M. she had just vomited a quantity of dark "bilious" fluid. Pulse 72 ; respiration 24 ; temperature $985^{\circ}$. Tongue clean and moist ; urine abundant, containing lithates, but no albumen. She complained of great pain in the abdomen, especially on the right side, and kept moaning, "Oh, the pain, the pain." There was no abdominal tenderness or tympanites; no swelling or lump could be felt, and there was no external hernia. The diagnosis was, "She is passing a gall-stone." Opium was prescribed, hot fomentations and brandy, \&c. On February 3 rd the symptoms continued; she vomited about every four hours. Before vomiting her face was sunken and distressed, and the pulse quickened to 120; after vomiting she became quite composed, and the pulse quiet. Nothing whatever passed per rectum; an enema was given and repeated, but only a very small quantity of fæces came away and a little flatus. Another enema was given on the 4 th, but returned quite clear. On the 5th the romiting began to be offensive; on the 6 th it was decidedly frecal in odour, and continued so on the 7 th and 8 th. During the first part of her illness she was chiefly under the care of Mr. Hallowes and Mr. Berridge. On the 6 th she was seen by Dr. Holman, and opium was treely given; on the 7 th matters had not mended, and it being evident that we had a case of acute intestinal obstruction to deal with, it was decided to explore the abdomen on the next day if there was no improvement. Accordingly, on Feb. 8th, or the seventh day of her illness, after consultation with Drs. Holman and Walters, and Mr. Hallowes, ether was given by Mr. Skelding at 4 P.M., and the abdomen opened by Dr. Walters with fall antiseptic precautions. An incision five inches long was made in the median line from the umbilicus downwards, and the hand introduced. A hard mass was found in the middle of the small intestines obstructing the bowel. The bowel was distended above the obstruction, collapsed and empty below. This was drawn to the surface, the gut opened by a longitudinal incision along its free margin, and a large impacted gall-stone removed. The wound in the bowel was closed with a continuous suture of carbolised silk, the bowel was then cleaned and returned into the abdominal cavity. The intestines were seen to beinjected and their peritoneal surface roughened. The abdominal wound was closed in the ordinary way. The patient was put to bed and given an opium suppository, and hot bottles to the feet, \&c. She had afterwards a little champagne and warm water to relieve flatulence. In the evening the patient seemed to have recovered from the shock of the operation and had no more vomiting. Pulse 84 ; respiration 24 ; temperature $99^{\circ}$. She passed a fair night, and had no pain or tympanites. The urine was drawn off by catheter. Next morning the pulse was 120 ; respiration 26 ; temperature $99^{\circ}$, and she appeared to be doing well. A bout2 P. M. she became rather suddenly collapsed, and died about 3 P.M.

At the autopsy next day a little recent peritonitis was found. The wound in the bowel looked healthy and was quite closed; it was about the middle of the small intestine. The liver was large and fatty; no gall-bladder could be found, but where it ought to have been the duodenum was adherent to the liver by a mass of fibrous tissue. On cutting into this some small fragments of gall-stones were seen in the duct. A ragged opening existed in the upper part of the duodenum where it was adherent to the liver. The abdomen was covered by a layer of fat three inches deep. Only the abdomen was inspected.

The points to which we would draw attention are: the suddenness of the attack; the complete obstruction; the small size of the stone to give rise to such severe symptoms; the facial aspect of the patient and the character of the pulse $(a)$ before, $(b)$ after vomiting; the relief after the operation; and comparatively easy death.

The reasons for thinking the obstruction was caused by a gall-stone were : the age of the patient; the sex, being a female; her sedentary habits and mode of life; previous history; and chiefly by excluding all other causes of acute obstruction. The stone will be in the museum of the forthcoming Congress.

Redhill.

\section{A ettirtor}

\section{HOSPITAL PRACTICE, BRITISH AND FOREIGN.}

Nulla antem est alia pro certo noscendi via, nisi quamplurimas et morborum et dissectionum historias, tum aliorum tum proprias collectas habere, et inter se comparare.-MorgagN I De Sed. et Caus. Morb., lib. iv. Procmium.

\section{ST. BARTHOLOMEW'S HOSPITAL.}

CASES OF PLEURISY TREATED BY TAPPING WITH FINE TROCAR, AND SUBSEQUENT SLOW DRAINAGE THROUGH CAPILLARY TUBING ATTACHED TO THE CANNULA. (Under the care of Dr. SouThEY.)

CASE 1. Pleurisy with large effusion, tapping and drainage; recovery._-Bridget $\mathrm{H}_{\text {___ }}$, aged twenty-six, was admitted on Oct. 1st, 1879, and might have been discharged on Oct. 20th, for she was quite well, but she was kept in some days longer. She illustrated the treatment of pleurisy with effusion by tapping and draining, admitting no air thereby.

At the end of August, 1879, she was confined. She got up on the sixth day, and took the child to the registrar. She got tired and sat down upon a doorstep and received a chill.

On Sept. 13th she had pain in her right side, followed by cough and dyspncea, but was able to go about and do her domestic duties up to Sept. 30th, when her breath was so short and cough so troublesome that she took to her bed.

On admission the right side of the chest was nearly full of fluid. Morphia was given to relieve the pain and quiet the cough, but while under observation to see what turn events would take, the urine diminished daily in quantity, and the temperature rose to $104^{\circ}$ at night, though only $99 \cdot 9^{\circ}$ in the morning. The heart was but little displaced, and the dyspnooa, except on disturbance, was small. Dr. Southey therefore decided to interfere, for the patient passed only a few ounces of urine each twenty-four hours, and perspired profusely.

On Oct. 3rd, with the finest trocar, a pint of greenish serum was drained off from between the fourth and fifth ribs, on the right side in axillary perpendicular line. The urine in the following twenty-four hours iucreased to two pints and a quarter, thereby illustrating immediate relief of pressure.

The patient was now purged with compound jalap powder, thirty grains every four hours, in the hope of thus 